\title{
ENHANCING EFL ADOLESCENT LEARNERS' VOCABULARY ACQUISITION VIA ONLINE SINGLE PLAYER ROLE-PLAY GAMES
}

\author{
Chien-Yu Lin, Yi-Huey Guo \\ Foreign Languages \& Literature Department, Tunghai University, \\ Taichung, Taiwan \\ E-mail: guoyh11@thu.edu.tw
}

Received: 2021-02-02

Accepted: 2021-03-27

\begin{abstract}
With the booming of digital gaming industry, numerous researchers have placed the focus on the use of online role-play games in language learning. However, the research focus of most prior studies was on the commercially-driven "massive multiplayer online role-play games" in the afterschool settings. The use of online single-player role-play games in the class was less studied. The present study hereby investigated sixty-five eighth graders' use of one online single-player RPG called OzHigh in vocabulary learning. The participants came from three classes in one public junior high school in central Taiwan. By means of a single group design, the participants underwent the game treatment, pre-test, post-test, delayed post-test, questionnaire, and the semi-structured interview. The results showed that the participants had significant improvement on their vocabulary performance. They also responded positively to their role-play game learning experience. Nevertheless, that did not mean that they held negative attitudes toward the traditional face-to-face method of vocabulary instruction. Instead, they confirmed the positive effects of both instructional methods and were aware of the varied learning purposes of these two methods. It is hoped that the findings of this study shed light on language teachers in their efforts to enhance their students' vocabulary learning.
\end{abstract}

Keywords: online role play games, vocabulary learning, adolescent EFL learners

\section{Introduction}

The growth of video gaming industries has changed many teachers' curriculum and instruction from face-to-face into digital game-based models (henceforth DGBL) (Tran, 2019). Over the years, numerous researchers have applied DGBL to different fields of teaching, including the field of history (Zin, Jaafar, \& Yue, 2009; Lee, Talib, Zainon, \& Lim, 2014), math (Ferguson, 2014), manufacturing (Perini, Luglietti, Margoudi, Oliveira, \& Taisch, 2017), and language teaching (Jalali, \& Dousti, 2012; Ryu, 2013).

In language research, issues revolving around DGBL have also been paid much attention, particularly in vocabulary teaching/learning. This may be partly caused by the fact that vocabulary memorization is a major obstacle faced by many EFL learners (Oxford, 1990) and that communication, without accurate use of vocabulary, cannot be achieved successfully (Wilkins, 1972). Although vocabulary learning is a fundamental task, many language learners did not consider it an interesting task (Nguyen \& Khuat, 2003). This is because many EFL 
learners often learn vocabulary by rote (Kim \& Gilman, 2008). In the rote-based vocabulary instruction, the instructor usually demonstrates the spelling on the blackboard and asks the students to practice writing/spelling/pronouncing of the new word. This traditional face-toface method of vocabulary instruction (also known as situational assistance), compared with $D G B L$, is less contextually-driven. Thanks to the development of DGBL, language teachers nowadays can provide their students with more contextually-driven learning experience.

Among various online games used in language learning, this study highlighted one specific type called online single-player role-play game (henceforth RPG). Prior studies tended to focus on the use of massive multiple-player ones (Rankin, Gold, \& Gooch, 2006; Rama, Black, Van Es, \& Warschauer, 2012) and drew on commercial games in the afterschool setting. Less research focus was placed on the use of non-commercial single-player RPGs in the in-class setting. Therefore, one online single-player RPG (i.e., OzHigh) out of a popular English learning platform (i.e., Cool English) was applied to adolescent EFL learners as a classroom activity for further investigation in this study.

In Taiwan, where the present study took place, its Ministry of Education had launched and funded one free English learning platform for adolescent English learners called Cool English (https://www.coolenglish.edu.tw/). Cool English highlights the acquisition of various language skills (including vocabulary, grammar, listening, speaking, reading, and writing) via game play. Different from other games developed for commercial purposes, Cool English is non-commercial. Its online single player RPGs are aimed for helping the users to acquire vocabulary in a contextually-driven way. Currently, there are more than 28,000 registered Cool English users.

This study observed three 8th grade classes' use of Cool English single-player online RPGs for vocabulary acquisition. The study attempted to address the following questions: 1 . Are there any significant differences in the participants' vocabulary learning performance after the RPG treatment? 2. What are the participants' attitudes toward the use of RPGs for vocabulary learning? 3. Are there differences in the participants' attitudes towards the RPG method and the traditional face-to-face direct method of vocabulary instruction?

\section{Literature Review}

\subsection{Characteristics of Educational Online Games}

In Sundqvist's (2013) SSI (scale of social interaction) model, online games can be divided into three types based on the number of players: single-player games that involve only one player; multiplayer games that involve two to thirty players; massively multiplayer online games that involve more than thirty players (henceforth MMOGs). Online games developed for educational purpose usually contain the following features: First, a storytelling narrative developed for enhancing players' sense of communal cohesiveness often serves as an initiative. Second, plenty learning opportunities are presented in the form of problemsolving tasks. Third, a safe space is often provided (particularly in young children's play) to allow players to construct their identities. These features benefit learners, allowing them to develop communicative competence and learning motivation out of the narratives, agencies, and content (Nardi, Ly, \& Harris, 2007; Bowman, 2010; Bowman, 2013; Hitosugi, Schidt, \& Hayashi, 2014).

Among studies on the use of online games in language learning, RPGs have been largely investigated (Hitchens, 2009; Sylven \& Sundqvist, 2012; Bytheway, 2015; Chien, 2019), most of which emphasized massively-multiplayer-online-role-play-games (henceforth MMORPGs). For example, Rama et al., (2012) integrated WoW (World of Warcraft) into college students' 
Spanish learning and concluded the positive use of online games on language learners' growth of communicative competence in the target language. Other studies using different MMORPGs such as EverQuest 2 (Rankin, Gold, \& Gooch, 2006) or Minecraft (Smolčec, Smolčec, \& Stevens, 2014) also had similar findings. MMORPGs provide players with authentic communicative practices via bilateral or mutual interaction \& communication (Steinkuehler, 2007). Such a characteristic reveals its socioculturally-relevant nature that learning takes place when learners interact with each other (Rama et al., 2012).

\subsection{Online Single Player Games}

Although the use of online games on language learning has been widely studied, less emphasis was placed on single game player's interaction in the virtual world. Prior studies on single-player games often looked at its effectiveness on learner's development of language skills such as listening (Anderson et al., 2008) and vocabulary acquisition (Miller \& Hegelheimer, 2006; Ranalli, 2008; deHaan, Reed, \& Kuwada, 2010; Jalali \& Dousti, 2012; Abrams \& Walsh, 2014). Many of them supported the positive use of game play in vocabulary learning. For example, Abrams and Walsh (2014) analyzed the use of one gamified single-player vocabulary learning platform called Vocabulary.com Challenge (The Challenge) on fourteen high school students in New York. They found that game-play made students become more active participants in the learning process. Regardless of the use in the in-school or after-school settings, the students showed vocabulary growth. Similarly, in college-level ESL courses, Miller and Hegelheimer (2006) and Ranalli (2008) also found that the use of one popular commercial single player RPG called The Sims assisted the learners in vocabulary acquisition.

Despite the positive use of online single-player RPGs in some classrooms, some studies had negative findings. For instance, deHaan, Reed, and Kuwada (2010) applied one music video game called Parappa the Rapper 2 to eighty Japanese college students learning English as a foreign language to see the game interactivity on second language learners' English vocabulary acquisition. The result showed that those playing the game recalled less vocabulary if compared with those watching their peers playing. This may be partly caused by the fact that the players were cognitively overloaded with vocabulary learning and game play at the same time. Therefore, they were distracted from the vocabulary recall. In another similar study (Jalali \& Dousti, 2012), game play was treated as a post-reading practice in traditional vocabulary instruction. One educational game called Student Multirom was used as a post-reading activity to enhance teenage EFL learners' vocabulary and grammar performance. Although the group playing the game were more active and motivated in the learning process, the result showed that there was no significance between the group treated with this post-reading game and the group that did not receive this treatment.

The aforementioned studies have implied the importance of selecting appropriate games for instructional use. For example, deHaan, Reed, and Kuwada's (2010) study on Japanese college EFL learners have shown that learners' development of reading and listening skills was greater than their vocabulary acquisition during gameplay. Therefore, a game well integrated into the beginning phase of vocabulary introduction seemed to be workable pedagogically. In short, prior researchers' results have shown that game play as a post-teaching practice with vocabulary taught in traditional method is of less effectiveness than the use of game play in the vocabulary introduction phase (Miller \& Hegelheimer, 2006; Ranalli, 2008; Jalali \& Dousti, 2012; Abrams \& Walsh, 2014). 
Enhancing EFL Adolescent Learners' Vocabulary Acquisition Via Online Single Player Role-Play Games, Chien-Yu Lin, Yi-Huey Guo

\subsection{Cool English Use in Classroom Settings}

With Cool English gaining popularity in Taiwan, its effectiveness has also been widely studied by local researchers. Most prior researchers concluded Cool English users' positive experience. For example, Chen (2016) investigated one class of elementary school students' attitudes toward the use of Cool English in a 15-week course. The participating students responded positively to their Cool English play. Another study (Wang, 2016) on $9^{\text {th }}$ graders' Cool English user experience, learning motivation, and academic performance also found students' increased motivation in English learning. They also showed improved performance on the post-test. Wang thus attributed the students' successful learning outcomes to Cool English's stimulating visual aids and game interactivity.

Findings of other relevant studies on the analysis of a specific language skill also accorded with the aforementioned ones. For example, in one speaking analysis study, Huang (2017) compared the speaking performance and speaking anxiety of two groups of $8^{\text {th }}$ grade EFL learners. One group practiced speaking with Cool English and the other practiced speaking face-to-face with their peers. The results showed students' alleviation of speaking anxiety in oral tests on the Cool English group. Additionally, Cool English users also had a significant improvement on their pronunciation, intonation, and fluency. In one reading analysis study, Li (2017) investigated the effectiveness of reciprocal teaching on Cool English users' reading comprehension and motivation. Although only high and intermediate-high level group of students showed improvement in reading comprehension, Cool English users' motivation in English reading was overall heightened. In another similar study, Wang (2017) applied Cool English and reciprocal teaching to junior high school students residing in rural areas. The result also showed that the students' English exam scores significantly improved. The participating students also agreed that they became more active and confident English learners via Cool English and reciprocal teaching.

Although online games or Cool English on heightening language learners' learning motivation and growth of language skills have been widely discussed, there is still a paucity of research on the use of non-commercial single player RPGs on students' vocabulary learning in the in-class setting. An inclusion of single-player RPG into investigation will add new threads to relevant studies.

\section{Research Method}

\subsection{Participants}

Research participants of this study were sixty-five eighth graders from three different English classes in one public junior high school in central Taiwan. They participated in this study voluntarily. According to the English teachers of this school, students' overall English proficiency levels in this school were considered "below average" if compared with the same age group in Taiwan.

\subsection{Methodological Procedure}

The methodological procedure of this study was framed by Groot's (2000) study on computer assisted vocabulary acquisition (CAVOCA) and Wang's (2016) study on EFL students' attitudes towards the use of technology in English learning. The data, collected in the Fall 2020, came from the following sources: pre-test, treatment, post-test, delayed posttest, questionnaires, and interviews. Different from Groot whose study divided the research participants into experimental group and control group, this study drew on a single group design. The reason was that the three participating classes' English proficiency levels were 
not equivalent. A single group design was thus administered to measure the participants' responses and performance after the treatment.

The study was based on a five-week-game-play treatment as the vocabulary instruction. In the first week, the participants played the first chapter's games to familiarize themselves with the interface and the game play. After that, they took the pretest. The purpose of having them take the pretest was to know their knowledge of the target vocabulary. In the second and the third week, the participants played the second and the third chapter's games. In these two weeks, each research participant adjusted his/her own pace by slowing down or speeding up the completion of the RPG tasks. Toward the end of the third week, they took the post-test, which was to know their immediate learning outcomes. In the fourth week, they took the delayed post-test without prior notice. They also answered the questionnaire in this week. In the last week, the participants were invited by the researcher for a semistructured interview.

To ensure that all the tests were of equivalent difficulty level, the researcher used the same set of test questions in the pretest, post-test, and delayed post-test. They were different only in the question order and the use of pronoun to replace previously mentioned nouns in the context. With respect to the delayed post-test, the participants were not informed in advance. The reason of doing so was based on Groot's (2000) suggestion that (1) it prevented the participants from paying extraordinary attention to the target vocabulary; (2) it helped the researcher to see the extent to which the game-play instruction worked in a realistic setting (Groot, 2000).

As suggested by Hubbard (2004) that having students familiarize themselves with the situated learning context and clear out unrelated tasks should be prioritized in the learning process, the present study also followed Hubbard's advice by including an additional interface training session prior to the start of the RPG session. Explanatory information of the game plot was provided to the participants. They also played the first chapter game to familiarize themselves with the interface and the game tasks.

Cool English's RPG - OzHigh (Chinese name Mó-Wù-Syué-Yuán) - is an educational singleplayer role-play game. OzHigh consists of four chapters featuring the school life setting. Throughout the gameplay, the players learn the English conversation and vocabulary simultaneously. The plot of OzHigh goes like the following: At the beginning of the game, everyone would be given an avatar named Marco. Macro was a new student admitted to the Oz Senior High School. However, as soon as he entered the campus, he was attacked by a dragon. Meanwhile, his school also faced numerous monsters' invasion and attack. To beat down the monsters and to save his school, Macro needed to find one missing magic stone as well as the stone-stealer. Marco is faced with two missions: surviving in the new school and beating down monsters (see Figure 2). In order to complete these two missions, the player needs to complete a number of vocabulary tasks in the game. The vocabulary tasks can be divided into three types: matching, categorizing, and true-or-false questions (as shown in Figure 3).

Every question popping up in the game needed to be answered correctly by the player so that he/she could move on to the next game. If he/she answered erroneously, a red cross would appear on the screen and that target word would automatically return to the target vocabulary list again. If the player answered the question correctly, a check would appear on the screen and the target word would be placed in the box, serving as an immediate feedback of this vocabulary task. According to Kiili (2005), such way of vocabulary acquisition is integral to digital game-based learning. 
Figure 2: The Two Missions
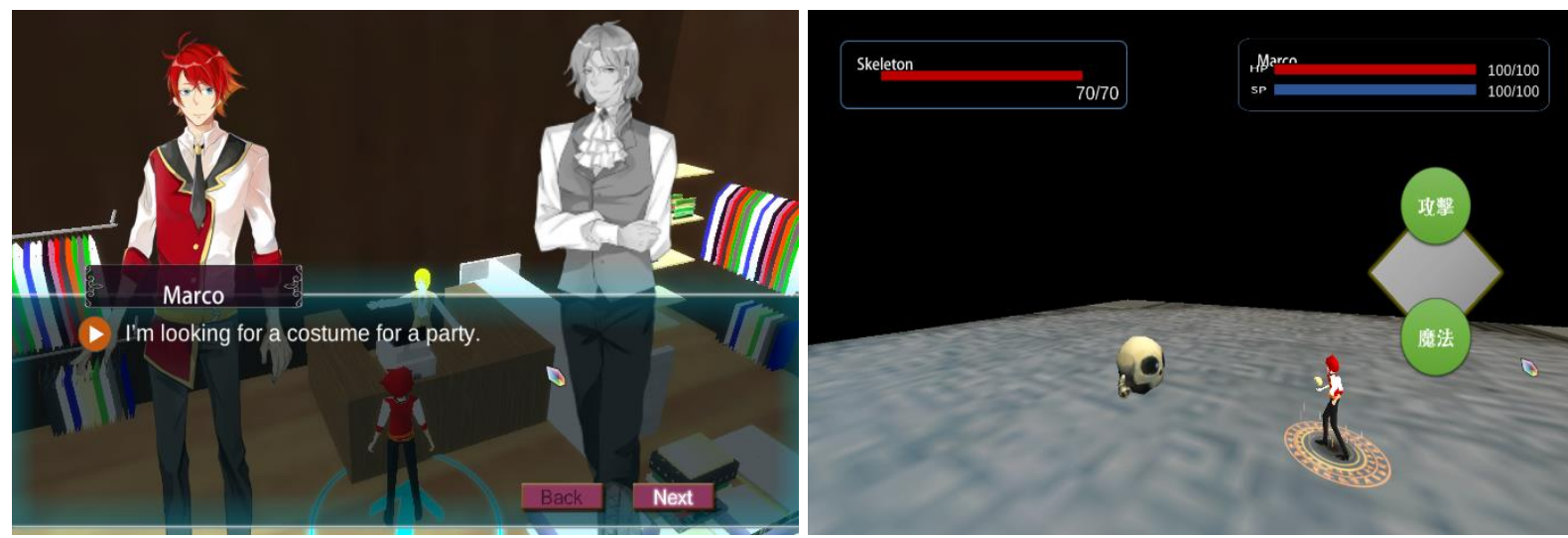

Note: The left is a screenshot of one game task, in which Marco needs to purchase clothes for the school party. The right is a screenshot of the battling-monster task. Both screenshots were taken from Cool English's RPG, OzHigh.

Figure 3: The Three Types of Vocabulary Task
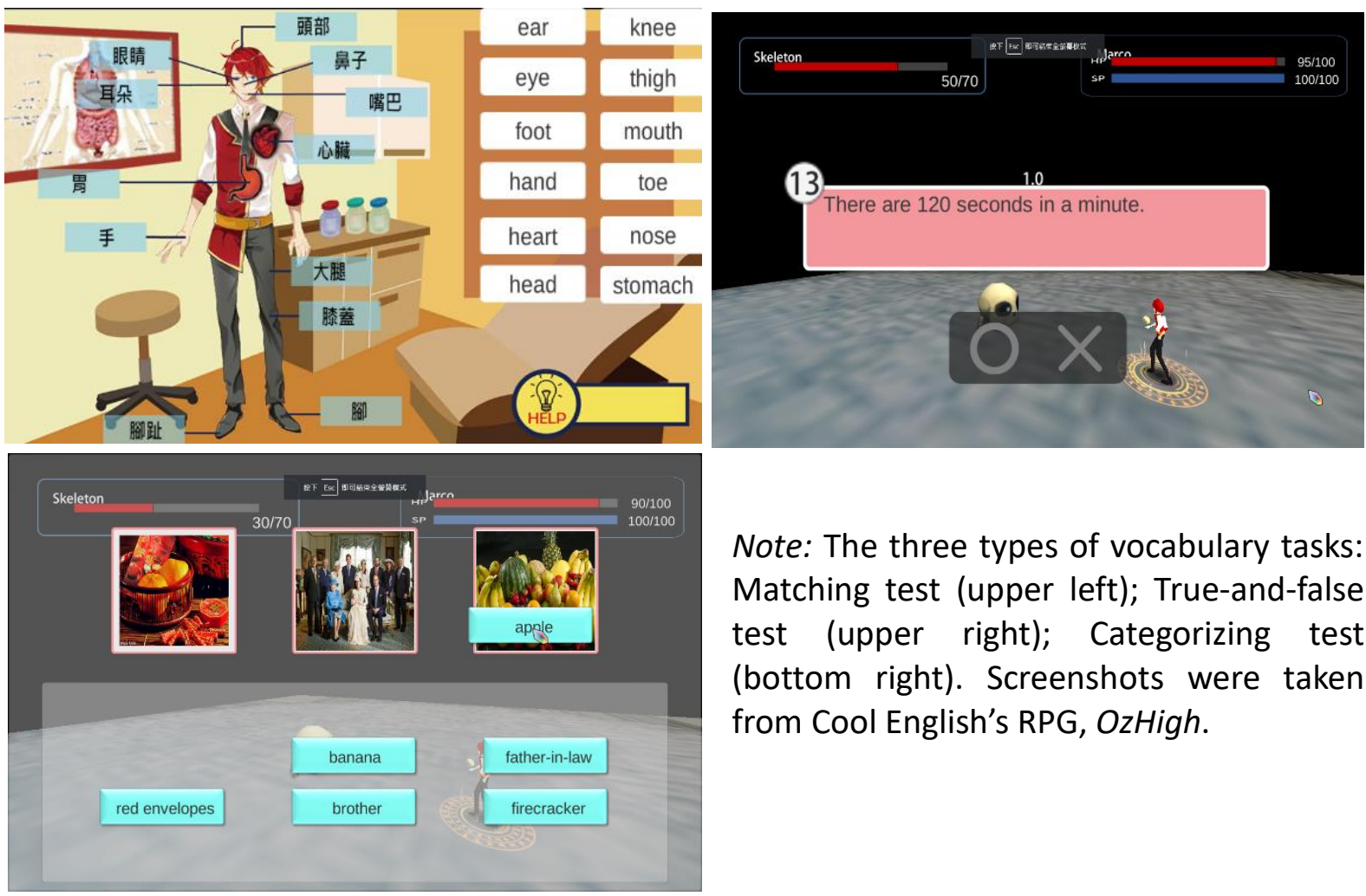

Note: The three types of vocabulary tasks: Matching test (upper left); True-and-false test (upper right); Categorizing test (bottom right). Screenshots were taken from Cool English's RPG, OzHigh.

After taking the post-test, the participants were asked to fill out a questionnaire aimed for knowing their attitudes toward the single-player RPG approach. The researcher adopted Chen's (2016) established questionnaire, which was developed to assess students' attitudes toward Cool English usage. Chen's questionnaire included four types of user-attitudes. The first two types featured Davis's (1989) technology acceptance model, the third type drew on Zarrad and Debabi's (2012) attitude model, and the last type derived from Liaw's (2008) behavioral intention model. A totality of 22 items following the five-point Likert scale was adopted (with 1 denoting "strongly disagree" and 5 denoting "strongly agree"). More specifically, these four types of user-attitude were arranged in the following order: perceived 
usefulness (a.k.a. PU) (Items 1-6), perceive ease of use (a.k.a. PEU) (Items 7-12), attitude (A) (a.k.a. Items 13-17), and behavioral intention (BI) (a.k.a. Items 18-22).

In addition to the questionnaire data, the researcher also invited the participants for a semi-structured interview and nine of them volunteered to participate in the interview. The interviews were conducted in Mandarin Chinese (the interviewees' native language) but were transcribed verbatim and translated into English.

\subsection{Data Analysis Procedures}

The scores of the pretest, post-test, and delayed post-test were analyzed by repeated measured ANOVA. Descriptive and independent-sample t-test were used to examine the means of each questionnaire item; frequencies and descriptive were employed to know the participants' preference for the single-player RPG approach.

\section{Results and Discussion}

\subsection{Effectiveness of the RPG method}

Mauchly's Test of Sphericity indicated that the assumption of the sphericity had not been violated $\left(p=.864>.005, \chi^{2}(2)=.292\right)$. The Tests of Within-Subjects Effects showed that $F(2,128)=13.503, p<0.001$, meaning that there are significant differences among the pre-, post-, and delayed post-test. Based on the scores of their means (shown in Table 1), there was improved vocabulary performance on the participants. The following Pairwise Comparisons Table (Table 2) showed that their improved performance between the pre-test and the post-test was significant. This proved the positive use of the single-player RPG as a classroom activity in vocabulary instruction. It was also in line with prior research (Lu \& Chang, 2016) that RPG games accelerate players' acquisition of semantic information (i.e., synonym and antonym words) and situational information (i.e., words acquired out of the context) of the target vocabulary. This positive outcome echoes prior researchers' call for game play as an alternative for foreign language learning (deHaan, Reed, \& Kuwada, 2010).

Of particular note is the statistical insignificance between their post- and delayed posttest scores. Presumably, their delayed post-test scores should be lower than their post-test scores since (1) they were not informed of taking this test in advance; (2) they did not complete all the game tasks at home. One possible explanation is that their delayed posttest scores (shown below) may be related to the sustainable effects of the RPG method.

\begin{tabular}{llll} 
& Table 1: & \\
& $\mathrm{N}$ & $\mathrm{M}$ & $\mathrm{SD}$. \\
\hline pretest & 65 & 50.15 & 25.89 \\
post-test & 65 & 57.62 & 28.11 \\
delayed post-test & 65 & 61.62 & 24.46 \\
\hline
\end{tabular}

Table 2: Pairwise Comparisons Table

\begin{tabular}{lllll}
$(\mathrm{I})$ & $(\mathrm{J})$ & $\mathrm{M}(\mathrm{I}-\mathrm{J})$ & $\mathrm{S} . \mathrm{E}$. & $\mathrm{p}$ \\
\hline pretest & post-test & $-7.462^{*}$ & 2.313 & .002 \\
\cline { 2 - 5 } & delayed post-test & $-11.462^{*}$ & 2.192 & .000 \\
\hline post-test & pretest & $7.462^{*}$ & 2.313 & .002
\end{tabular}


Enhancing EFL Adolescent Learners' Vocabulary Acquisition Via Online Single Player Role-Play Games, Chien-Yu Lin, Yi-Huey Guo

\begin{tabular}{lllll} 
& delayed post-test & -4.000 & 2.210 & .075 \\
\hline delayed post-test & pretest & $11.462^{*}$ & 2.192 & .000 \\
\cline { 2 - 5 } & post-test & 4.000 & 2.210 & .075 \\
\hline
\end{tabular}

\subsection{Students' Attitudes toward OzHigh}

The questionnaire data showed that the participants' attitudes toward the use of OzHigh for vocabulary learning were overall positive. This could be explained by Prensky's (2001) assertion that "digital natives" like the research subjects, compared with those who were deficient in digital literacy, were more aware of applying or integrating video games into learning. The mean of the four aspects of user attitudes were: PU (3.67), PEU (3.83) A (3.75), BI (3.12). Their feedback was generally positive except two BI items, one of which asked their possibility of re-using OzHigh in the after-class occasions. The other revolved around their interest in using this game on a long term basis. Their answers on these two items were less positive due to the reasons that (1) there were other activities to attract them in their personal life settings; (2) there were only four chapters of games in the OzHigh; however, the participants had already completed most of the games during the course of the study. Playing this game repeatedly or on a long term basis became less appealing to them. Regarding this, Yip and Kwan (2006) also pointed that students showed less interest in playing the same vocabulary game repeatedly if the game failed to provide them with continuous challenge.

Except the aforementioned situations, they responded positively in using the RPG for vocabulary learning (Item 18, M =3.09). According to the interview data, more than half of the interviewees (i.e., five out of nine) even played the remaining games in their leisure time. Their curiosity about the game's storylines accounted for their continuing play. As for those who did not play, they expressed interest in completing the remaining gameplays if they could be given more free time. According to Pluck and Johnson (2011), such interest is beneficial to students' learning as it leads to their development of intrinsic motivation.

Table 3: Mean Score of the Items on the Questionnaire perceived usefulness (PU)

1. Using Ozhigh helps me achieve the English learning goals faster

2. Using Ozhigh improved my vocabulary learning performance

M. SD

3. Using Ozhigh improved my English ability

$3.55 \quad 1.03$

4. Using Ozhigh makes me learn vocabulary more efficiently

3.510 .99

$3.75 \quad 1.08$

5. Using Ozhigh makes learning vocabulary easier

$3.66 \quad 1.03$

6. Ozhigh is helpful to vocabulary learning

$3.60 \quad 1.12$

perceived ease of use (PEU)

7. Learning to use OzHigh is easy for me

$3.97 \quad 1.02$

8. Using Ozhigh to accomplish my learning goals is easy

$3.77 \quad 0.96$

9. The interface of Ozhigh is clear and easy to understand

$3.68 \quad 1.02$

10. Ozhigh is flexible to interact with

$3.69 \quad 1.07$

11. It would be easy for me to become skillful at playing OzHigh

$3.81 \quad 0.93$

12. OzHigh is easy to use

$4.06 \quad 0.93$

attitude $(\mathrm{A})$

13. Using OzHigh to learn vocabulary is pleasant

$3.92 \quad 1.14$

14. Using OzHigh to learn vocabulary is convenient

$3.88 \quad 1.11$

15. Using OzHigh to learn vocabulary is interesting

$3.77 \quad 1.20$ 
16. Using OzHigh to learn vocabulary is inviting

17 Using OzHigh to learn vocabulary is satisfying

13. Using OzHigh to learn vocabulary is pleasant

behavioral intention (BI)

\begin{tabular}{lll}
\hline 18. I would spend time using OzHigh after class & 2.88 & 1.32 \\
19. I would spend more time using OzHigh for vocabulary learning & 3.09 & 1.30 \\
20. I would play OzHigh for long term use for vocabulary learning & 2.91 & 1.22 \\
21. I would try other chapters of OzHigh & 3.58 & 1.20 \\
22. I would introduce OzHigh to others & 3.20 & 1.41 \\
\hline
\end{tabular}

\subsection{Student Responses: RPG Method versus Direct Method}

Although the participants showed improved vocabulary performance via the RPG treatment and admitted the fun brought by the RPGs, it was interesting to note that their like of RPGs did not mean that they disliked or undermined the value of traditional face-toface method of vocabulary instruction. According to the interview data, they generally agreed that the RPG method was a stress-relieving, fun, and relaxing way of vocabulary learning. For instance, Interviewee G stated that "no one stares at you in the Cool English class... which makes taking class less stressful." Similarly, Interviewee D also mentioned that "with OzHigh, you can learn the vocabulary via game play, which is joyful...Taking regular classes is sometimes very stressful yet playing the game allows me to release my stress, which is very good." Compared with the "stressful" or "stale" image of the traditional vocabulary instruction, the RPG instruction provided them with a friendlier, more multimodal, and more multifaceted learning environment. This part of finding echoed Wang's (2013) assertion that the integration of technology into language instruction to some extent alleviates students' stress.

Nevertheless, some participants addressed their concerns about the RPG method. First, compared with the traditional vocabulary instruction, textual information of the target vocabulary provided in the RPG instruction was somewhat limited. Some of them held that the traditional face-to-face method allowed the teachers to provide them with richer textual information of the target vocabulary. Second, the RPG method failed to provide students with adequate teacher-student interaction. The teacher-student face-to-face interaction was often desired and expected by the students yet it was achievable only via the traditional face-to-face method. Interviewee F's words best described this situation: "Teachers can tell us jokes when teaching vocabulary... However, when using the RPG method, we just keep clicking the mouse." Additionally, compared with the traditional vocabulary instruction, there were some technicity problems of the RPG instruction such as the malfunctioned game buttons or the poor sound effect. Some OzHigh's malfunctioned game buttons caused the participants failure to place correct answers in the matching boxes in time, resulting in a delay of the game play. Sometimes, the sound effect (such as the echoing sound) caused confusion to some of them.

As stated earlier, although the participants enjoyed and benefited from the RPG method, it did not mean that they undermined the value of the traditional vocabulary instruction. Instead, some participants addressed the essential role of the traditional face-to-face method. For example, Interviewee F spoke highly of the RPG method yet she still favored the traditional vocabulary instruction:

The traditional way of vocabulary teaching is mainly rote learning. Playing the game, on the contrary, enables you to play, to know the storyline, and 
then to understand the meaning of the new word...I prefer the traditional method because there is more interaction in the class. The teacher interacts with us more by providing more information such as the tips of memorizing and tell us jokes.

Different from the traditional face-to-face method, the RPG method required the participants to learn independently by either acquiring information from online dictionaries or learning directly out of errors they made in the game tasks. Such an automated learning approach was different from the cramming and banking model of education they were familiar with. Their unfamiliarity with RPG method's automated learning has resulted in their preference for the traditional face-to-face method. More specifically, they tended to rely on their teachers as the main source of knowledge. Therefore, they somehow expected their teachers to jump in to provide them with target vocabulary information so that they could solve the game tasks smoothly. For example, Interviewee A stated that "I prefer that the teacher integrated RPG games and activities into the lecture. That way, the teacher can solve my questions immediately and give me the answers right away. This allows me to learn more effectively." Another student - Interviewee D - commented on the automated learning feature of the RPG method: "Playing RPGs requires you to learn and to comprehend on your own. Compared with the RPG course sessions, I think the teacher's lecture is easier to understand."

The aforementioned finding shows the influence of one's situated learning culture on the selection of his/her preferred instructional approach. Some participants' preference for traditional vocabulary instruction may be explained by Loh and Teo's (2017) proposition that students in Asia participated less actively by relying on teachers for knowledge receiving and depositing. A student-centered as well as automated learning approach like the RPG game was thus at odds with the teacher-led instruction to which they were accustomed. One interviewee's answer may well conclude the students' like of both instructional approaches: "The RPG method is a better instructional approach for reducing our stress of learning. However, the traditional method is a better approach for achieving our learning outcomes." Such perception was analogous to Groot's (2000) finding in an earlier study.

To sum up, the participants improved their vocabulary performance by means of the single player RPGs. They also held positive attitudes toward this new method and considered it a less stressful way of learning vocabulary; however, that does not mean that they were against the traditional face-to-face method of vocabulary instruction. Instead, their attitudes towards the two methods were quite positive. Different from the traditional vocabulary instruction, the RPG method provided the participants with interesting and fun learning experience yet it failed to provide them with rich information pertaining to the word's origin, definition, usage, and examples. On the contrary, the traditional face-to-face method allowed the teacher to provide students with richer information of the target vocabulary; however, it also brought boredom as well as stress to the participants. Such finding is in line with Hays' (2005) earlier claim that learning via game play, in spite of making one's learning objective more achievable, does not make it a superior instructional approach.

\section{Conclusion}

This study investigated the effectiveness of a new vocabulary learning approach - the online single-player RPG method. Although the participants' attitudes toward the traditional face-to-face method of vocabulary instruction were also discussed, the aim of this study was 
not to demonstrate which method was better. Instead, it is hoped that the findings unravelled in this study can provide language teachers with an alternative in their attempts to enhance their students' vocabulary learning.

The results of this study have shown that the use of an online single player RPG method in the in-class setting worked effectively on EFL adolescent learners' vocabulary learning. Such effect was even sustainable. Of particular note is that these "digital natives" responded positively to the digitally-driven instruction as well as the traditional face-to-face vocabulary instruction. Both methods met the participants' satisfaction in learning. The RPG method made their learning interesting and less stressful; the traditional method brought them direct access to the word's usage. Yip and Kwan (2006) stated that prior researchers tended to highlight students' recognition of the importance of an integrated approach in language instruction but overlooked their need for a traditional instruction. This study went one step further to fill the gap and to call for language teachers paying attention to students' need for traditional instruction and re-examining its value in the students' situated culture of learning.

The participants' positive responses to both methods imply their need for an integrated approach for the maximization of their learning outcomes. This study hereby makes some pedagogical suggestions, hoping to shed light on future studies: (1) supplementary course materials that enhance students' vocabulary acquisition deserved to be developed and included in the RPG course sessions; (2) future researchers may investigate how learners' English proficiency levels and personality traits affect their like/dislike of the RPG method; (3) a genre analysis on the game elements is needed to help us better understand what specific game elements work for language learners; (4) game developers may consider an inclusion of richer textual information and storylines in the RPG for educational purposes.

\section{References}

Abrams, S. S., \& Walsh, S. (2014). Gamified Vocabulary. Journal of Adolescent \& Adult Literacy, 58(1), 49-58. https://doi.org/10.1002/jaal.315

Anderson, T. A., Reynolds, B. L., Yeh, X. P., \& Huang, G. Z. (2008, November 17-19). Video games in the English as a Foreign Language Classroom [Paper presentation]. IEEE International Conference on Digital Game and Intelligent Toy Enhanced Learning, Banff, BC, Canada. https://doi.org/10.1109/DIGITEL.2008.39

Bowman, S. L. (2010). The Functions of Role-Playing Games: How Participants Create Community, Solve Problems and Explore Identity. Oxford: McFarland \& Company.

Bowman, S. L. (2013). Social Conflict in Role-Playing Communities: An Exploratory Qualitative Study. International Journal of Role-Playing, 4(4), 4-25.

Bytheway, J. (2015). A Taxonomy of Vocabulary Learning Strategies Used in Massively Multiplayer Online Role-Playing Games. CALICO Journal, 32(3), 508-527. https://doi.org/10.1558/cj.v32i3.26787

Chen, Y. C. (2016). Exploring EFL Elementary Students' Language Experience on Using Cool English (Master's thesis, National Yunlin University of Science and Technology, Yunlin, Taiwan). Retrieved from http://ndltd.ncl.edu.tw

Chien, Y. C. (2019). The Language of Massively Multiplayer Online Gamers: A Study of Vocabulary in Minecraft Gameplay. TESL-EJ, 23(3). http://www.teslej.org/pdf/ej91/int.pdf

Davis, F. D. (1989). Perceived Usefulness, Perceived Ease of Use, And User Acceptance of Information Technology. MIS Quarterly, 13(3), 319-340. https://doi.org/10.2307/249008 
Enhancing EFL Adolescent Learners' Vocabulary Acquisition Via Online Single Player Role-Play Games, Chien-Yu Lin, Yi-Huey Guo

deHaan, J., Reed, W. M., \& Kuwanda, K. (2010). The Effect of Interactivity with a Music Video Game on Second Language Vocabulary Recall. Language Learning \& Technology, 14(2), 74-94.

Ferguson, T. (2014). Mathematics Achievement with Digital Game-Based Learning in High School Algebra 1 Classes (Doctoral dissertation, Liberty University, Virginia, USA). Retrieved from https://digitalcommons.liberty.edu/

Groot, P. J. (2000). Computer Assisted Second Language Vocabulary Acquisition. Language learning \& technology, 4(1), 56-76.

Hays, R. T. (2005). The Effectiveness of Instructional Games: A Literature Review and Discussion (Report No. NAWCTSD-TR-2005-004). Florida, USA: Naval Air Warfare Center Training Systems Division.

Hitchens, M., \& Drachen, A. (2009). The Many Faces of Role-Playing Games. International Journal of Role-Playing, 1(1), 3-21.

Hitosugi, C. I., Schmidt, M., \& Hayashi, K. (2014). Digital Game-Based Learning (DGBL) in the L2 Classroom: the Impact of the Un's Off-The-Shelf Videogame, Food Force, on Learner Affect and Vocabulary Retention. CALICO Journal, 31(1), 19-39. https://doi.org/10.11139/cj.31.1.19-39

Huang, P. P. (2017). The Effect of Online English Speaking Training Lessons on Speaking Performance and Speaking Anxiety of Eighth Graders (Master's thesis, Tunghai University, Taichung, Taiwan). Retrieved from https://ndltd.ncl.edu.tw

Hubbard, P. (2004). Learner Training for Effective Use of CALL. In Fotos, S. \&, Browne, C. M. (Eds.), New perspectives on CALL for second language classrooms (pp. 45-68). Routledge.

Jalali, S. \& Dousti, M. (2012). Vocabulary and Grammar Gain Through Computer Educational Games. Gema Online Journal of Language Studies, 12(4), 1077-1088.

Kiili, K. (2005). Digital Game-Based Learning: Towards an Experiential Gaming Model. The Internet Higher Education, 8(1), 13-24. https://doi.org/10.1016/j.iheduc.2004.12.001

Kim, D., \& Gilman, D. A. (2008). Effects of Text, Audio, and Graphic Aids in Multimedia Instruction for Vocabulary Learning. Journal of Educational Technology \& Society, 11(3), 114-126.

Lee, G. H., Talib, A. Z., Zainon, W. M. N. W., \& Lim, C. K. (2014). Learning History Using RolePlaying Game (RPG) on Mobile Platform. In Jeong, H. Y., Obaidat, M. S., Yen, N. Y., \& Park, J. H. (Eds.), Advances in computer science and its applications (pp. 729-734). Springer Science \& Business Media.

Liaw, S. S. (2008). Investigating Students' Perceived Satisfaction, Behavioral Intention, and Effectiveness of e-learning: A Case Study of the Blackboard System. Computers \& education, 51(2), 864-873. https://doi.org/10.1016/j.compedu.2007.09.005

Miller, M., \& Hegelheimer, V. (2006). The SIMs Meet ESL Incorporating Authentic Computer Simulation Games into the Language Classroom. Interactive technology and smart education, 3(4), 311-328. https://doi.org/10.1108/17415650680000070

Nardi, B. A., Ly, S., \& Harris, J. (2007, January 3-6). Learning Conversations In World of Warcraft [Paper presentation]. 40th Annual Hawaii International Conference on System Sciences, Waikoloa, HI, USA. https://doi.org/10.1109/HICSS.2007.4

Nguyen, T. T. H. \& Khuat, T. T. N. (2003). The Effectiveness of Learning Vocabulary Through Games. Asian EFL Journal Quarterly, 5(4), 90-105. 
Oxford, R. (1990). Language Learning Strategies: What Every Teacher Should Know. Newbury House.

Perini, S., Lugliettia, R., Margoudib, M., Oliveirac, M.,Taischa, M. (2017). Training Advanced Skills for Sustainable Manufacturing: A digital Serious Game. Procedia Manufacturing, 11, 1536-1543. https://doi.org/10.1016/j.promfg.2017.07.286

Pluck, G. and Johnson, H. L. (2011). Stimulating Curiosity to Enhance Learning. GESJ: Education Sciences and Psychology, 2(19). http://eprints.whiterose.ac.uk/74470/1/

Prensky, M. (2001). Digital Natives, Digital Immigrants Part 1, On the Horizon, 9(5), 1-6, https://doi.org/10.1108/10748120110424816

Rama, P. S., Black, R, W., van Es, E. A., \& Warschauer, M. (2012). Affordances for Second Language Learning in World of Warcraft. ReCALL, 24, 322-338. https://doi.org/10.1017/S0958344012000171

Ranalli, J. (2008). Learning English with the Sims: Exploiting Authentic Computer Simulation Games for L2 Learning. Computer Assisted Language Learning. 21(5), 441-455. https://doi.org/10.1080/09588220802447859

Rankin, Y. A., Gold, R., \& Gooch, B. (2006). 3D Role-Playing Games as Language Learning Tools. Eurographics (Education Papers), 25(3), 33-38.

Ryu, D. (2013). Play to Learn, Learn to Play: Language Learning Through Gaming Culture. ReCALL, 25, 286-301. https://doi.org/10.117/S0958344013000050

Smolčec, M., Smolčec, F., \& Stevens, V. (2014). Using Minecraft for Learning English. TESL-EJ, 18(2), 1-15.

Steinkuehler, C. (2007). Massively Multiplayer Online Gaming as a Constellation of Literacy Practices. E-Learning, 4(3), 297-318. https://doi.org/10.2304/elea.2007.4.3.297

Sundqvist, P. (2013). Categorization of Digital Games in English Language Learning Studies: Introducing the SSI Model. In Bradley, L. \& Thouësny, S. (Eds.), 20 years of EUROCALL: Learning from the Past, Looking for the Future (pp. 231-237). Research-Publishing.net

Sylvén, L. K., \& Sundqvist, P. (2012). Gaming as Extramural English L2 Learning and L2 Proficiency among Young Learners. ReCALL, 24(3), 302-321. https://doi.org/10.1017/S095834401200016X

Tran, B. (2019). Advanced Methodologies and Technologies in Media and Communications. IGI Global. https://doi.org/10.4018/978-1-5225-7601-3.ch002

Wang H. H., \& Chen, H. L. (2017). The Effects of Reciprocal Teaching on English of Junior High School Students on the Remote Island - A case study of Col English Learning Platform as Medium (Master's thesis, , National Taiwan Normal University, Taipei, Taiwan). Retrieved from DSpace at National Taiwan Normal Univ.

Wang, S. Y. (2016). The Effects of Online Learning Platform "Cool English" Integrated into English Teaching on Junior High School Students' Learning Motivation and Learning Achievement (Master's thesis, Shu-Te University, Kaohsiung, Taiwan). Retrieved from https://www.airitilibrary.com/

Wilkins, D. (1972). Linguistics in Language Teaching. Edward Arnold Publishers.

Yip, F. W., \& Kwan, A. C. (2006). Online Vocabulary Games as a Tool for Teaching and Learning English Vocabulary. Educational media international, 43(3), 233-249.

Zarrad, H., \& Debabi, M. (2012). Online Purchasing Intention: Factors and Effects. International Business and Management, 4(1), 37-47.

Zin, N. A. M., Jaafar, A., \& Yue, W. S. (2009). Digital Game-Based Learning (DGBL) Model and Development Methodology for Teaching History. WSEAS Transactions on Computers, 8(2), 322-333. 